\title{
Development of real-time monitoring system using wired and wireless networks in a full-scale ship
}

\author{
Bu-Geun Paik ${ }^{1}$, Seong-Rak Cho ${ }^{1}$, Beom-Jin Park ${ }^{1}$, Dongkon Lee ${ }^{1}$, Byung-Dueg Bae ${ }^{2}$ \\ ${ }^{1}$ Maritime \& Ocean Engineering Research Institute, KORDI, Daejeon, Korea \\ ${ }^{2}$ Korea Maritime University, Busan, Korea
}

\begin{abstract}
In the present study, the real-time monitoring system is developed based on the wireless sensor network (WSN) and power line communication (PLC) employed in the 3,000-ton-class training ship. The WSN consists of sensor nodes, router, gateway and middleware. The PLC is composed of power lines, modems, Ethernet gateway and phase-coupler. The basic tests show that the ship has rather good environments for the wired and wireless communications. The developed real-time monitoring system is applied to recognize the thermal environments of main-engine room and one cabin in the ship. The mainengine room has lots of heat sources and needs careful monitoring to satisfy safe operation condition or detect any human errors beforehand. The monitoring is performed in two regions near the turbocharger and cascade tank, considered as heat sources. The cabin on the second deck is selected to monitor the thermal environments because it is close to the heat source of main engine. The monitoring results of the cabin show the thermal environment is varied by the human activity. The real-time monitoring for the thermal environment would be useful for the planning of the ventilation strategy based on the traces of the human activity against inconvenient thermal environments as well as the recognizing the temperature itself in each cabin.
\end{abstract}

KEY WORDS: Ship;Real-time monitoring; Thermal environment; Wireless Sensor Network (WSN); Power Line Communication (PLC).

\section{INTRODUCTION}

Marine ships are going on the seas and experience diverse sea conditions. A ship has different requirements according to its type and purpose. A commercial ship carries various cargos to the destination ports within a given period. Different from the commercial ship, comfort and convenience are needed in a passenger or cruse ship. Military ships should have mobility and the capabilities to carry out its mission. Most important of all, since a ship stays on the seas most of the time during its operation, greater convenience must be provided to its crew and passengers so that the efficiency and safety of its operation could be ensured.

A lot of ship management technologies aimed at increasing the efficiency and safety of a ship have been developed and proposed by many researchers. The EU (European Union), which is home to many research institutes and classification societies, has developed intelligent hullmonitoring systems to reduce the risk of structural failure, spills into the sea, damage to cargo, and for improved passenger safety and comfort (MARINTEK, 2000). Nguyen and Nelson (2001) discussed an approach to integrating data collection and analysis of ship machinery for the assessment

Corresponding author: Bu-Geun Paik

E-mail:ppaik@moeri.re.kr of the conditions and operational performance of the ship's equipment. Nielsen et al. (2006) introduced the concept of the onboard management of wave-induced structural loads and ship motions through the measurement of relative wave motions, bending moment, and so on. Most of the previous studies have used cables such as Ethernet or optic fibers to transmit the detected and collected data. However, the realtime monitoring using only conventional wired cables has lots of difficulties such as making new holes on steel plates and additional significant costs in the existing ships. Although wired cables may be considered for a new ship in advance, the sensing will be allowed in a fixed and specific region where they are already deployed.

Besides the above ship managements, the services for the crew and passengers of ships are getting more important. Although there are many opportunities to have a convenient and safe life on land, such as through home automation or home network systems (Hankem and Misson, 2002), tracking systems (Oppermann et al., 2006), security or safety systems, and health care systems (Hodges et al., 2006), it is not easy to enjoy more convenient environment on a ship. Recently, Paik et al. (2009) reported the studies on WSN characteristics for ship application and related basic experimental results. They showed the usefulness of WSN in a full-scale ship application; however, actual ship needs some suitable wired networks in the specific regions to avoid any hindrance caused by the inherent nature of ship because the WSN can 
not transmit sensor data at the environments surrounded by thick steel walls. For the crew and passengers of ship on the seas, it is necessary to establish more efficient and serviceable environments using ubiquitous technologies like WSN and PLC.

In this study, the real-time monitoring system based on WSN and PLC was developed as a trial to provide convenient environments on a real ship, and the basic characteristics of WSN and PLC were examined in the ship. Besides the employment of WSN and PLC, the thermal environments were investigated in the main engine room and one cabin to prepare valuable reference data in terms of safety and convenience using the real-time monitoring system.

\section{REAL-TIME MONITORING SYSTEM USING WSN AND PLC}

Several communication methods for transmitting data from one device to another have been developed all over the world. These methods are generally classified into wired and wireless communications. They include power line communications, Home PNA (phoneline networking alliance), Ethernet, IEEE1394 (a serial bus interface standard for high-speed communications), and USB (universal serial bus) for wired communications, and RFID (radio frequency identification), Zigbee, Home RF (a wireless networking specification for home devices to share data), Bluetooth, IEEE 801.11, and UWB (ultra-wide-band) for wireless communications.

Among these communication technologies, $2.4 \mathrm{GHz}$ Zigbee were chosen for wireless communication so that ship data can be gathered everywhere. Zigbee, which has low power consumption, was developed only recently. It is composed of many sensor nodes, which can send sensor data to the router; a router, which gets the data from the sensor node and passes it on to the sink node (gateway); and a sink node, which connects it to internet service or middleware. Middleware is a general term for any programming that serves to glue together between two separate and often already existing programs. A common application of middleware is to allow programs written for access to a particular database to access other databases. Typically, middleware programs provide messaging services so that different applications can communicate. The Zigbee system can connect with many sensors such as for temperature, humidity, light, vibration, etc., so it can be a small network with a maximum of 255 nodes per sink node. Because of this advantage, it can communicate more with other devices than can Bluetooth and home RF, and is a low-cost yet effective network. A schematic diagram of the wireless sensor network field is shown in Fig. 1. Data transmitting from gateway to middleware can be delivered outside the sensor network field through the satellite communication or other communication networks. The WSN is treated conveniently because it needs rather smaller cost than wired network and its sensor module has small size to move easily. In addition, routing technique in the data communication is getting higher the usage and the reliability of the WSN.

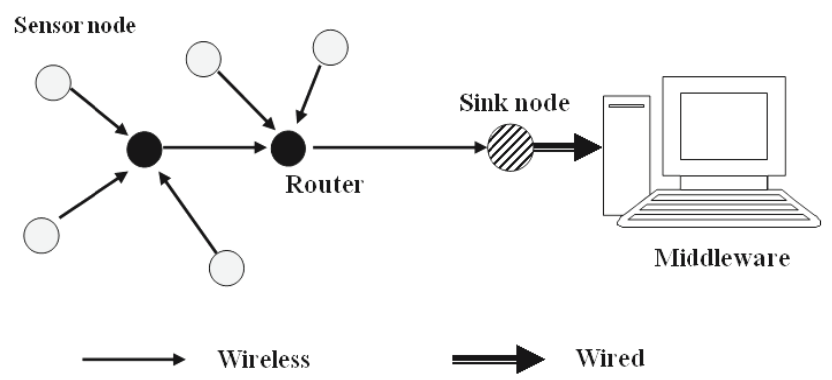

Fig.1 Wireless sensor network system for a ship.

PLC (power line communications) is a wired data communication technology that uses the power line in a house, company, factory or anywhere else where it is available. Technologies such as coupling between the power line and a signal, signal decoding, and noise filtering have been developed. It may be easy to set up and cheaper than other wired communication technologies. The speed of its data transfer has increased only recently to $200 \mathrm{Mbps}$. While other wired communication technologies such as Ethernet must be installed separately, PLC could be tested directly, since the power line already exists in the ship. In the present study, PLC with the data rate of $9.6 \mathrm{kbps}$ has been used to aware sensing data in the ship because it has been known to have more stable performance than PLC with higher data rate.

\section{REAL-TIME MONITORING IN THE FULL-SCALE SHIP USING WSN AND PLC}

\section{Construction of network environments using WSN and PLC}

The particulars of the ship that was chosen for this study are shown in Table 1. Hannara, a 3,000-ton-class training ship, has relatively many cabins because it was designed to be sailed to train many students.

Table 1 Particulars of the ship Hannara.

\begin{tabular}{|l|l|}
\hline Length $(m)$ & 102.7 \\
\hline Width $(m)$ & 14.5 \\
\hline Height $(m)$ & 7 \\
\hline Tonnage $($ ton $)$ & 3640 \\
\hline Speed $($ knot $)$ & 15 (max. 17$)$ \\
\hline Main Engine & $4,000 H P$ diesel engine \\
\hline
\end{tabular}

Fig. 2 and Fig. 3 show photos of Hannara and its general arrangement, respectively. The deckhouse of Hannara consists of the following, arranged vertically (from the bottom to the top): the bottom deck, which houses the mainengine room; the $2^{\text {nd }}$ deck, for the accommodations of visitors; 
the main deck, for the accommodations of students; the shelter deck, for the accommodations of the crew, the boat deck, for the accommodations of faculty members; the training deck, for navigation training; and the bridge deck, which is used as a wheel house.

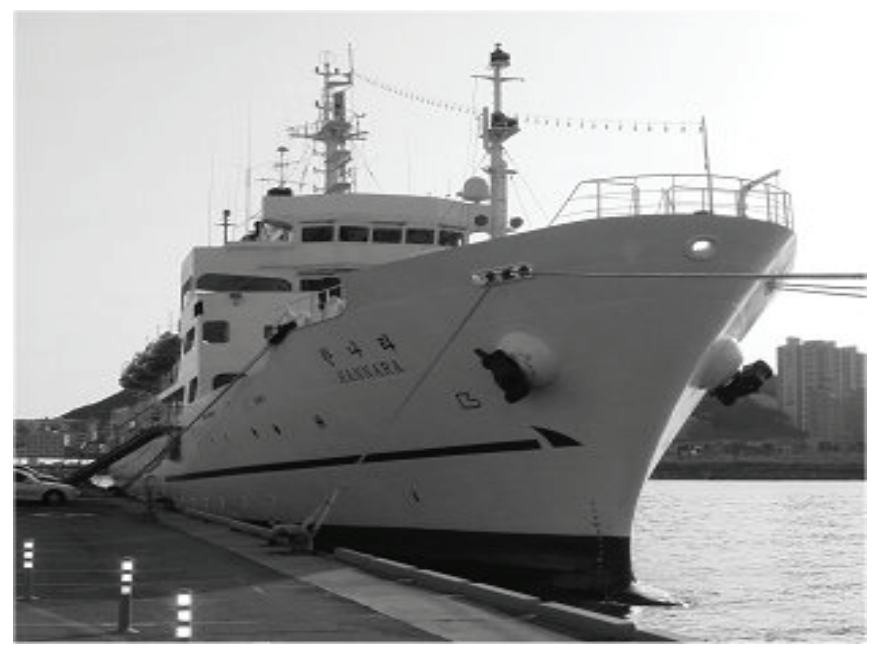

Fig. 2 Hannara for full-scale ship experiments.

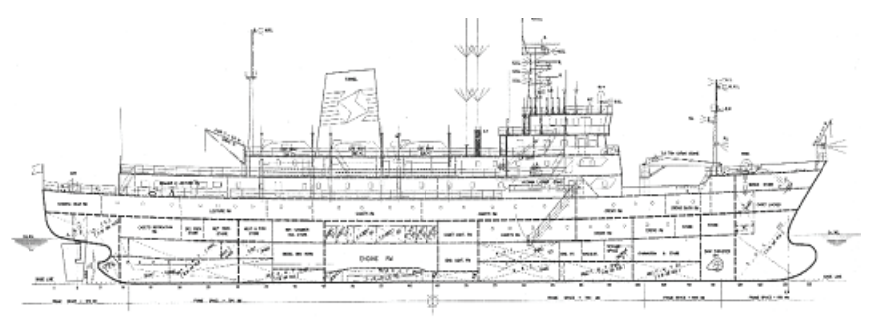

Fig.3 General arrangement of Hannara.

The basic WSN tests were conducted when the ship was moored to the port and when all the equipments in the mainengine room, except for the electric generator, were not being operated. The wireless communication tests were done in one cabin at the shelter deck, which is the middle deck of the ship. The door of the cabin was made of steel but its surface was covered with smooth materials. Data transmission tests were carried out using two ZPAs (Zigbee Protocol Analyzers), one sending 100 10-byte packets and the other receiving those packets. The RF (radio frequency) strength as well as the number of packets, was measured to evaluate the transmission quality. When the sending ZPA (located within the cabin) and the receiving ZPA (located outside the cabin) were $1 \mathrm{~m}$ away from the door, a $98 \sim 100 \%$ delivery ratio (= received packet number/sent packet number) and an RF strength of $-27 \sim-30 \mathrm{dBm}$ were found, which are not bad for wireless communication. Here, $d B m$ is an abbreviation for the power ratio in decibel $(d B)$ of the measured power referenced to one milliwatt $(\mathrm{mW})$. Zero $\mathrm{dBm}$ equals one milliwatt, which means the maximum power.

The next basic tests for WSN were carried out in the main-engine room on the bottom deck and $2^{\text {nd }}$ deck during 10 hours. In the main engine room, there are many types of equipment such as water pumps, motor, purifiers, compressors and something like those. Since lots of equipments as well as ship walls are made of steel, the data delivery loss caused by the fading effect should be considered before the actual data gathering. Nine sensor nodes were deployed in the main engine room and the packets from each sensor nodes were monitored in the control room. Besides the test in the main engine room, other experiments on the delivery ratio were prepared in the normal cement building office $(4 m \times 3 m \times 3 m)$ and the steel container $(6 m \times 2.5 m \times 2.5 m)$ as a the test bed without any equipment there. Those additional results were compared with that in the main engine room to find out the extent of data loss. Table 2 shows the delivery ratios obtained in the main engine room of the ship, steel container and building office. The worst case was the ship with lots of equipments causing multi-path and fading effects. Each node in the steel container has similar delivery ratio to those in the office. Even though the harsh environment of steel walls in the steel container, the fading effect due to the multi-path seems to be not high in the conditions of rather narrow space and no obstacles. All the sensor nodes except light sensor node in the main engine room show $2 \sim 7 \%$ less delivery ratio than normal office condition. It was found that measured delivery ratio and RF strength of $-10 \sim-35 \mathrm{dBm}$ in the main engine room were enough to provide RF environments for the deployment of the WSN.

Table 2 Comparison of the delivery ratio in WSN.

\begin{tabular}{|c|c|c|c|c|}
\hline Area & Node & $\begin{array}{c}\text { Ship } \\
(\%)\end{array}$ & $\begin{array}{c}\text { Steel container } \\
(\%)\end{array}$ & $\begin{array}{c}\text { Office } \\
(\%)\end{array}$ \\
\hline \multirow{7}{*}{ M/E } & Router & 86.21 & 94.71 & 93.68 \\
\cline { 2 - 5 } & Router & 84.11 & 86.78 & 86.03 \\
\cline { 2 - 5 } & Temp. & 82.16 & 81.04 & 85.76 \\
\cline { 2 - 5 } & Router & 86.07 & 85.01 & 92.62 \\
\cline { 2 - 5 } & Light & 88.31 & 88.35 & 88.37 \\
\cline { 2 - 5 } & $\mathrm{CO}$ & 82.81 & 81.64 & 84.76 \\
\cline { 2 - 5 } & Gas & 85.84 & 86.57 & 87.34 \\
\cline { 2 - 5 } & Temp. & 85.49 & 86.85 & 86.09 \\
\cline { 2 - 5 } & $\mathrm{CO}_{2}$ & 75.37 & 71.19 & 79.5 \\
\hline
\end{tabular}

Usage of WSN may produce several problems. The one problem that was found concerns the battery consumption of the sensor nodes, and even of the routers. As most of the companies that are producing WSN modules design and manufacture these through approximate estimation, without accurate information regarding battery consumption, useful reference data must be obtained. Power consumption tests were found to be necessary in terms of the sensing interval. In this experiment, sensing interval was 13 seconds and the corresponding lifetime of the battery was about two days. If 
we increase the sensing interval to 1 minute, the lifetime could be about 15 days. Especially, as the use of gas sensors for fire prevention will require significant power consumption, it might be better to adopt a regular power service, as the occasion demands.

The other problem that was found concerns microwave diffraction. In the present study, the routers and sensor nodes were placed within the line of sight because there were no reference data about the diffraction. This, however, is not efficient for the design for real-time monitoring because the communication depth can be consumed in vain to avoid obstacles within the line of sight. The basic data related to microwave diffraction are necessary for more effective WSN design.

Because of the inherent nature of a ship, most areas in Hannara divided by steel walls with the thickness over $10 \mathrm{~mm}$. In addition, since complicated structures may appear among decks or passages and reduce the delivery ratio of WSN, appropriate matching between wireless and wired communication networks is necessary. In the present study, wired communication technology of PLC was considered to establish ubiquitous environments in the ship besides the wireless communication network. For the investigation of PLC environment in Hannara, basic experiments were conducted when its main engine and electric generator were operating. As Hannara has the 3-phase power line, the 3phase coupler called PCDC(Fig. 4) of the moderate speed PLC(9.6kbps) was installed in a distributing board and it was connected with the Ethernet gateway called ECGW to transmit the collected data toward the middleware. Figure 5 exhibits the typical network arrangement of WSN and PLC deployed in Hannara. The monitoring room having middleware was located in the Seminar room as shown in Fig. 5.

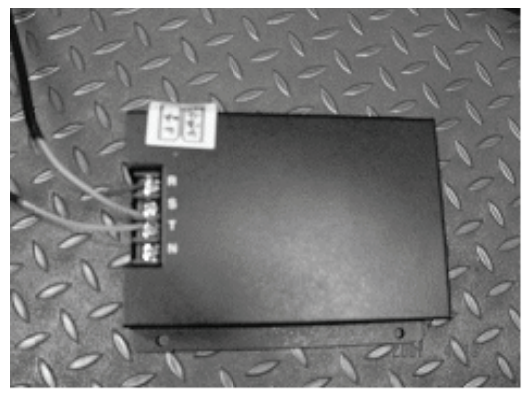

Fig. 4 3-phase coupler for 9.6kbps PLC.

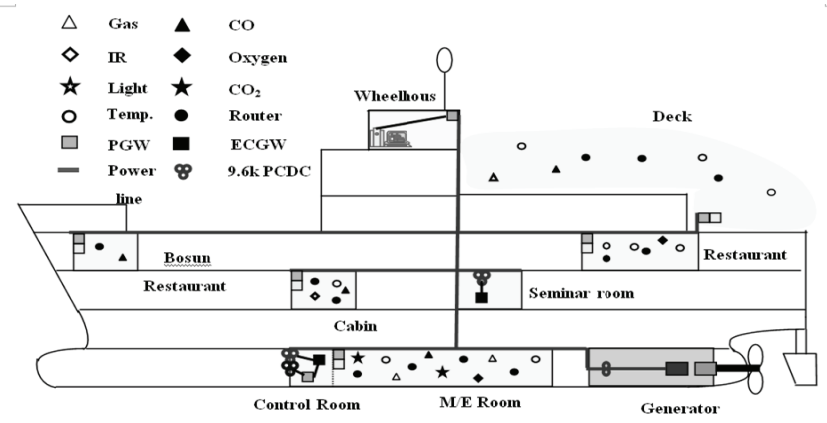

Fig. 5 Typical network arrangements in a ship.
The PLC quality was checked at several areas such as a cabin, restaurant, bridge, store, and tested areas show good delivery ratio over $80 \%$ except the bosun store. Bosun store seems to have separate power line system different from that of deck house and has the delivery ratio below 50\%. Figure 6 shows the delivery ratios acquired in the main engine room, test bed (steel container) and cement office. The sensing data were gathered for about three hours in all places. Especially, the measurements in the ship were conducted at night and day for same hours, respectively. Main engine room also showed good delivery ratio over $80 \%$ and context awareness can be done continuously without any communication interruption. However, comparing with the results on land, it was found that the reduction of delivery ratio was $2 \sim 5 \%$ in most of sensor nodes of the ship. It is conjectured that the abrupt operation of equipments or abrupt increase of electric power consumption generated some noises and influenced on the data transmission through power lines. Although the delivery ratio of PLC was not bad, additional preparation such as noise filter would be needed to prevent the sharp decline of PLC quality. In addition, more systematic studies on PLC should be followed in a ship to figure out the sources of noises or load distribution among power lines.

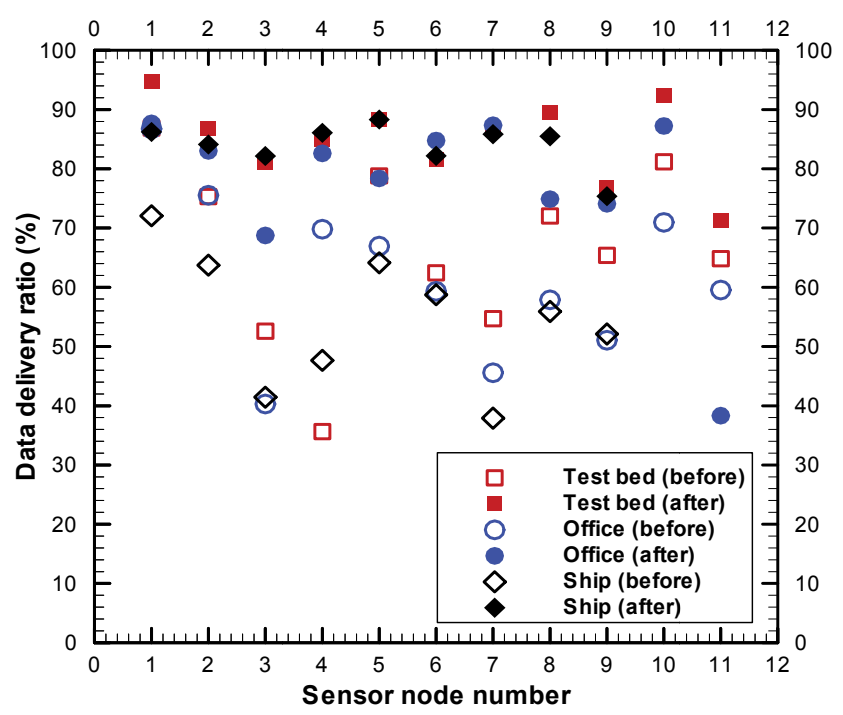

Fig. 6 Data delivery ratio of PLC in the main engine room.

In the real-time monitoring system, WSN was used at the areas satisfying line-of-sight condition and PLC was employed at the areas where WSN is not available. Coastal navigation from Busan to Jeju Island was selected for actual experiments. Especially, temperature data in the main engine room and a cabin were collected at winter season to evaluate the developed ubiquitous environments established by WSN and PLC.

\section{Thermal Environments in the Main-Engine Room}

The real-time monitoring system based on the WSN and PLC was employed in the main-engine room, which had lots 
of equipments and was considered to be very important in the monitoring of the ship's environmental conditions. The main engine and the electric generator were operated during the real-time monitoring. Fig. 7 shows the main-engine room viewed from the main-engine control room, and the laptop computer and sink node were placed on the control console.

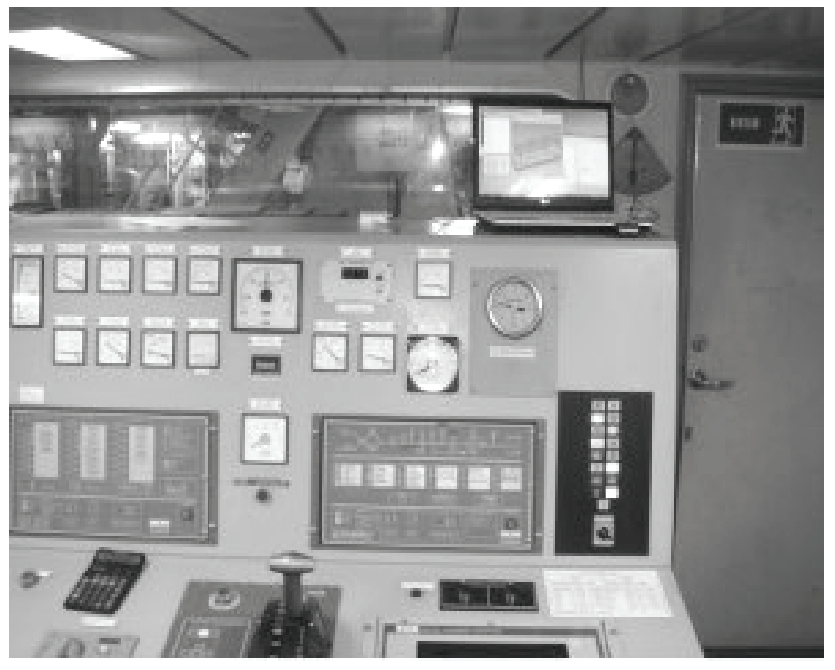

Fig.7 Control room for main-engine operation.

As various equipment, valves, and pipes, as well as the main engine, were arranged in a complex way inside the main-engine room, it was necessary to properly deploy the routers (Fig. 8) and sensor nodes.

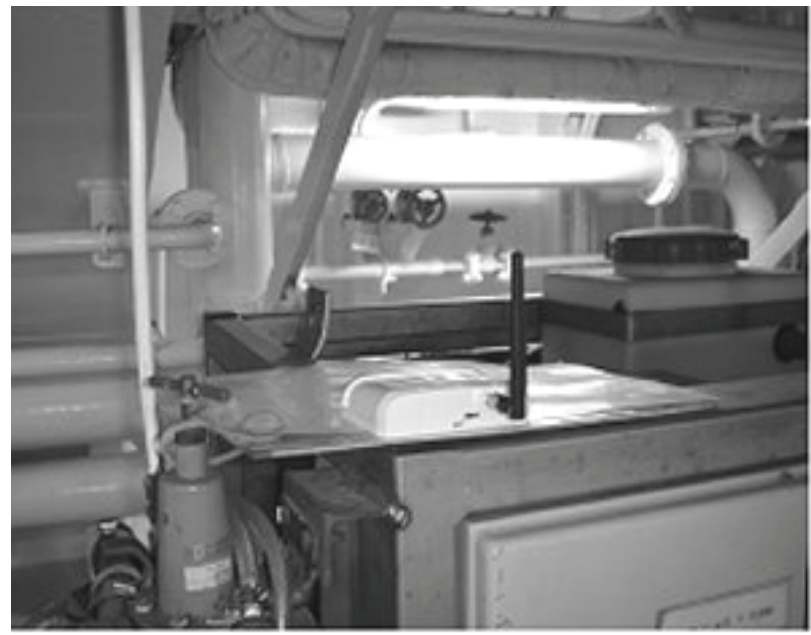

Fig. 8 Router for the WSN in the main-engine room.

The real-time monitoring of thermal environments in the main engine room is important to keep the safe ship operation because it has some equipment or compartment as heat sources. The obvious heat sources in the main engine room are main engine itself, boiler, cascade tank for boiler, turbocharger for exhaust gas and some compartments around the funnel. In the present study, we focused on the thermal environments near the cascade tank and the turbocharger. The cascade tank supplies cooled water to the boiler, and then the water heated in the boiler returns to it. Thus, as the cascade tank always has hot water, the real-time monitoring of cascade tank is necessary to estimate the states of the boiler or related equipments. A turbocharger (short for turbine driven supercharger) is an exhaust gas driven forced induction supercharger used in internal combustion engines. The turbine inlet receives exhaust gases from the engine exhaust manifold causing the turbine wheel to rotate. This rotation drives the compressor, compressing ambient air and delivering it to the air intake of the engine; this allows more fuel to enter the cylinder of engine because the air is compressed. Because the initial temperature of the exhaust gas is high, the real-time monitoring of the turbocharger and funnel would be also useful for recognizing the operation condition of the diesel engine. Although the monitoring in the main-engine room was carried out in the winter season, it should be done more carefully for the heat sources in the summer season or a tropical voyage.

Fig. 9 shows the arrangement of the sensor nodes for temperature and routers in the main engine room. The sink node, indicating the gateway, was placed at the top of the console, whose height was $1.7 \mathrm{~m}$, inside the control room. Router 1 was placed at the top of an equipment that was $6 \mathrm{~m}$ away from the sink node and that had a height of $1.7 \mathrm{~m}$. Router 2 was placed at the top of a cylindrical steel structure that was $7 \mathrm{~m}$ away from router 1 and that was beside the stairs leading to the $2^{\text {nd }}$ deck. Router 3 was placed at the entrance door to the $2^{\text {nd }}$ deck, and was about $4 \mathrm{~m}$ away from router 2. Finally, the sensor nodes were positioned at the appropriate places based on the communication depth. The first temperature sensor node was deployed near the cascade tank of the bottom deck where the main engine was located. The second temperature sensor node was deployed very near the turbocharger of the second deck which is just over the bottom deck. The sensor nodes and routers communicated with each other by hopping technique, from the main-engine control room to the turbo-charger of the $2^{\text {nd }}$ deck.

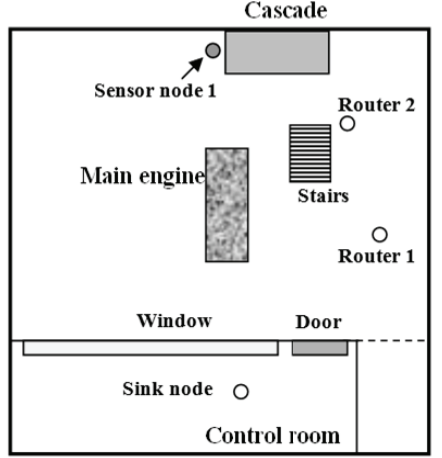

(a) Bottomdeck

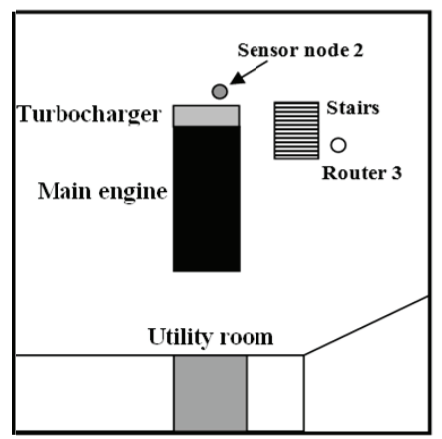

(b) Second deck
Fig. 9 Deployment of WSN routers and sensor nodes (top view).

In the real-time monitoring, the routers and sensor nodes were employed at places within the line of sight. Although the real-time monitoring that was conducted on a real ship was generally successful, there was additional problem concerning the communication depth of the WSN. Router 3 
could allow its children to have only a fourth depth because the total depth of this WSN was four. Although the ship Hannara has a rather small main-engine room, only partial monitoring of both the bottom and $2^{\text {nd }}$ decks was done due to the limited communication depth of the WSN. Therefore, it is necessary to increase the communication depth of the WSN in advance in order to monitor two decks simultaneously.

Table 3 shows the operation schedule ordered by the ship captain. After the operation of bow thruster to leave the pier, the main engine operated and the ship speed increased gradually to $13.6 \mathrm{Knots}$. When the ship had the full speed at $14: 15$, it was confirmed that all the equipment were normally operated in the main-engine room. Before the ship sailing, the main engine experienced warming up process and the temperature of turbocharger had been increased gradually. However, it increased abruptly from the sailing time of 14:15 for about two hours, and thereafter the region near the turbocharger had the steady temperature distribution of $34 \sim$ $36^{\circ} \mathrm{C}$ as shown in Fig. 10. Figure 10 also shows the state of the cascade tank as the increase of the ship speed. Although the temperature near the cascade tank increased gradually according to the increment of the loading of the main engine, the highest temperature was less than $32^{\circ} \mathrm{C}$ and there was no abrupt increase of the temperature. It seems that the operation of the cascade tank did not relate closely to that of the main engine. This sort of real-time monitoring and the fast estimation of current situation would provide helpful information to find out any human errors or any failures of equipment in advance.

Table 3 Ship operation schedule ordered by the captain.

\begin{tabular}{|l|l|}
\hline Time & Operation \\
\hline $14: 00$ & Bow thruster start \\
\hline $14: 03$ & Bow thruster stop \\
\hline $14: 05$ & Main engine operate (SLOW) \\
\hline $14: 13$ & Main engine operate (HALF) \\
\hline $14: 15 \sim$ & Main engine operate (FULL) \\
\hline
\end{tabular}

\section{Thermal Environments in the Cabin}

Although a typical cabin has the ventilation unit to adjust the flow rate of heated or cooled air, this kind of unit should be controlled directly by the crews and might give discomforts to them because of the poor ventilation process. Most of all, different thermal environments will appear in each cabin according to the various locations and its purpose in spite of the simultaneous operation of air conditioning in the ship. In this study, one cabin was chosen to monitor the thermal environments in real time. The cabin was located on the $2^{\text {nd }}$ deck and influenced by the heat generated by the main engine. There were two wooden bunk beds and one wooden table in the cabin. The cabin is very important place for crews to have a rest or sleep and the thermal environment around the bed should be carefully treated. As the upper and lower beds of a bunk were considered to have different environments, one temperature sensor node was placed near the upper bed (top) and the other node was placed near the lower bed (bottom) of one bunk. The measured temperatures were so high when a person enters the cabin at 12:00 as shown in Fig. 11.

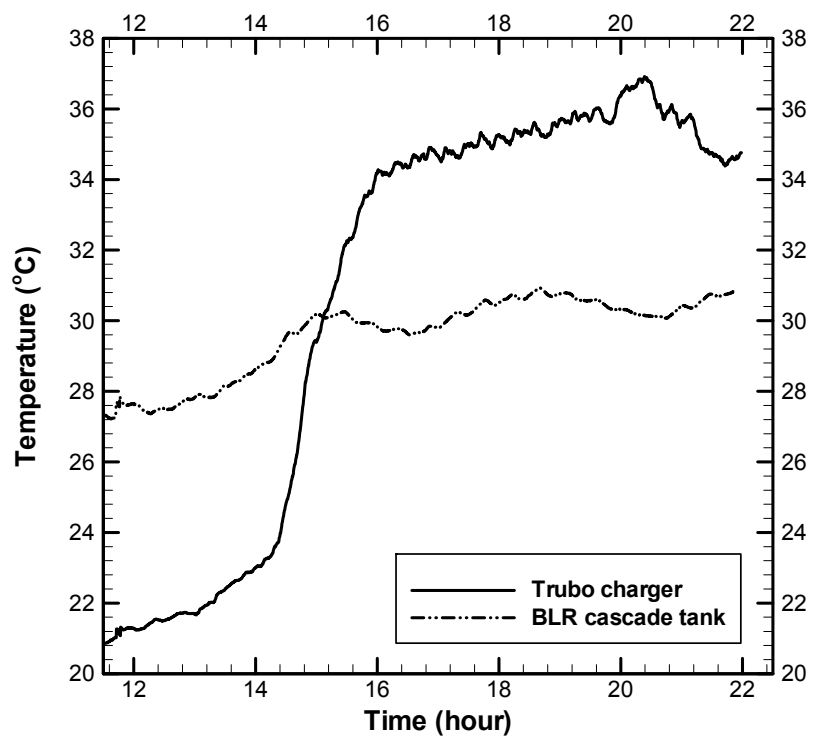

Fig. 10 The time history of thermal environment in the mainengine room.

Since the temperature over $36^{\circ} \mathrm{C}$ is not a good condition for human living, the crew opened the door of the cabin to decrease the ambient temperature of the cabin. Figure 11 shows the temperature decrease due to incoming of external air during one hour from 13:00 to 14:00.

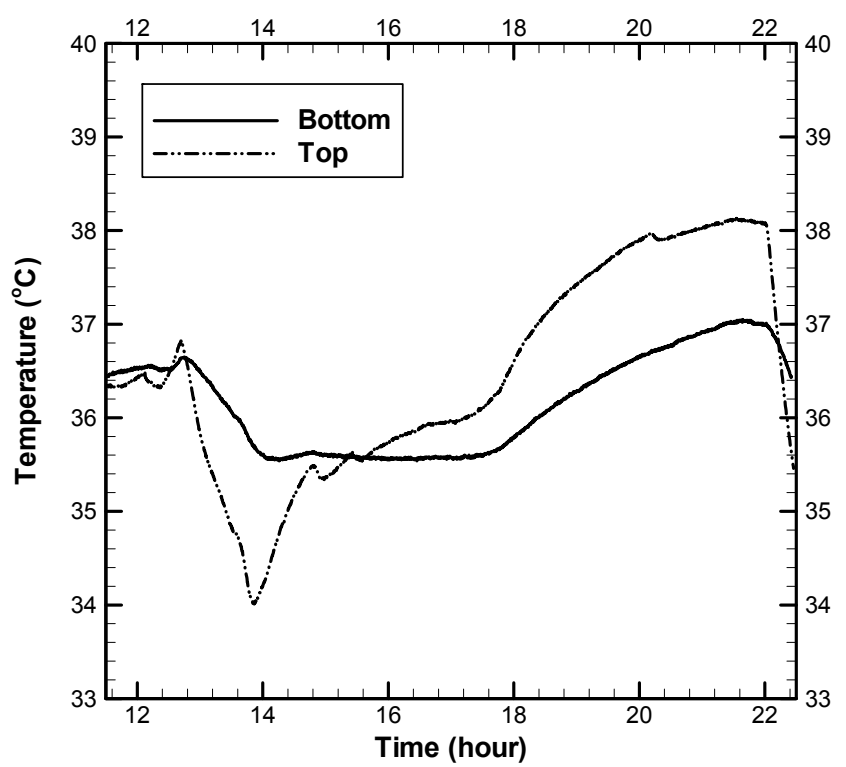

Fig. 11 The time history of thermal environment in one cabin. 
It was also found that the temperature around the upper bed was more sensitive to the inflow from the outside, compared with that around the lower bed. Just before the taking-off of the ship at 14:00, the crews went to the upper deck and closed the cabin door. The temperature started to increase and thereafter the highest temperature near the upper bed became to about $38^{\circ} \mathrm{C}$. The crews returned to their cabin at 22:00 to open the door again and operated the airconditioner to lower the cabin temperature. From 22:00 the temperature decreased largely because of the corresponding human activities. The temperature near the upper bed was controlled well by the human activities; however, the region around the lower bed has relatively harsh thermal environments. To service more comforts to the crew on the lower bed, it is recommended to modify the location of current ventilation unit or add another one near the lower bed. Generally, the thermal environments of cabins have been controlled by one management center in a ship and have not been considered seriously. The adoption of the system to monitor the thermal environment of a cabin in real time would be useful for the investigation of human activity against inconvenient environments as well as the monitoring of the temperature, providing important information on the improvement of the human living or comfortableness in a ship.

\section{CONCLUDING REMARKS}

In this study, ubiquitous technologies such as WSN and PLC were employed to establish real-time monitoring system in a full-scale ship. WSN was distributed in several areas and the collected data were transmitted to middleware by using PLC. The ubiquitous environments structured in the ship would be applied in various fields in a ship because it recognized well the sensing data.

For the application of the developed real-time monitoring system, the thermal environments in the main engine room and one cabin were investigated. The monitoring results show that the operation of the main engine changed the thermal environments in the main-engine room and increased the temperature of the turbocharger to $37^{\circ} \mathrm{C}$ from $21^{\circ} \mathrm{C}$. The real-time monitoring in the main engine room would play a role of helping to estimate any human errors or any failures of equipments in advance.

The cabin on the $2^{\text {nd }}$ deck was affected directly by heat sources of main engine. The monitoring results show the highest temperature of $38^{\circ} \mathrm{C}$ and the variation of the thermal environments by the human activities.
The real-time monitoring for the thermal environment would be useful for the planning of the ventilation strategy, which is based on the data of the human activities against inconvenient thermal environments, as well as the detecting the temperature itself of each cabin.

\section{ACKNOWLEDGEMENT}

This research was accomplished with support from the inherent research project entitled "Development of smart operation technologies for exploration fleets based on the ubiquitous concept (PE0120A)."

\section{REFERENCES}

MARINTEK.2000. Intelligent hull-monitoring systems for the reduced risk of structural failure, spill into the sea, and damage to cargo, and for improved passenger safety and comfort (HULLMON+). G3RD-CT-2000-00329, EU Framework Programme.

Nguyen, T.V. and Nelson, H.W., 2001. A systems approach to machinery condition monitoring and diagnosis.Proceedings of the $4^{\text {th }}$ Annual Systems Engineering Conference. 22-25 October 2001.

Nielsen, J.K. Pedersen, N.H.Michelsen, J. Nielsen, U.D. Baatrup, J. Jensen, J.J. andPetersen, E.S., 2006. Sea sense: real-time onboard decision support. Annual Report, Force Technology.

Paik, B.G. Cho, S.R. Park, B.J. Lee, D.K. Bae, B.D. and Yun, J.H., 2009. Characteristics of wireless sensor network for full-scale ship application. J. Marine Science \& Technology, 14(1),pp. 115-126.

Hakem, N. andMisson, M., 2002.Study of the throughput of the wireless home automation network using the encapsulation of two medium-access methods.Proceedings of Communication Systems and Networks.9-12 September 2002,Spain.

Oppermann, L. Broll, G. Capra, M. andBenford, S., 2006.Extending authorizing tools for location-aware applications with an infrastructure visualization layer. Proceedings of Ubiquitous Computing.17-21 September 2006, USA.

Hodges, S. Williams, L. Berry, E. Izadi, S. Srinivasan, J. Butler, A. Smyth, G. Kapur, N. and Wood, K., 2006. SenseCam: a retrospective memory aid. Orange County, Proceedings of Ubiquitous Computing. 17-21 September 2006, USA. 